\title{
Self-perception and Parents’ Perceptions of the Nutritional Status Based on BMI in School Children of Dhaka City
}

\author{
Md Shameem, ${ }^{1}$ Md. Belal Uddin, ${ }^{2}$ Jesmin Jahan, ${ }^{3}$ A N M Nurul Haque Bhuiyan, ${ }^{4}$ \\ Md Rustam Ali, ${ }^{5}$ Bidhan K Pramanik $^{6}$
}

\begin{abstract}
Background \& objective: Childhood underweight or overweight prevention efforts are unlikely to be successful without a better understanding of how parents perceive the problem of underweight or overweight in their children. This study was carried out with the objective of comparing perceptions (parents' and self) of the nutritional status with the actual nutritional status measured by BMI.

Materials \& Methods: This Cross-sectional study was carried out in the Department of Pediatrics, Sir Salimullah Medical College, Mitford hospital, Dhaka over a period of 12 months, from July 2008 to June 2009. Three schools in Dhaka Metropolitan city were selected by multistage sampling (lottery method). A self- administered parents' questionnaire was filled by parents. Then the student's nutritional status was defined according to age and gender specific body mass index percentile from CDC-2000 reference as underweight $\left(<5^{\text {th }}\right.$ percentile), normal $\left(5^{\text {th }}-85^{\text {th }}\right.$ percentile), overweight $\left(85^{\text {th }}-\right.$ $<95^{\text {th }}$ percentile), ) and obese (95th percentile and above). Chi-square test was used for testing statistical significance.

Results: This study found the double burden of undernutrition and obesity in school children of Dhaka city (41.4\% as underweight, $48.5 \%$ as normal weight, $5.6 \%$ as overweight, and $4.5 \%$ as obese). Obesity (6\% vs. $2.2 \%)$ and overweight $(6.6 \%$ vs. $2.2 \%)$ was higher in boys than girls, although underweight was almost similar (42\% vs. $41 \%)$ in boys and girls. Majority of children (602 among 1026) failed to perceive their actual body image (58.7\%) and almost half of the parents (371 among 772 ) also failed to perceive the actual body image of their children (48.1\%). Among underweight, overweight and obese children $87.3 \%$ had incorrect self-perception of nutritional status. $75 \%$ of parents' perception was incorrect in the above mentioned group.
\end{abstract}

Conclusion: Underweight and obese school children had the most incorrect self-perception. Similarly parents of the underweight and obese children group had the most incorrect parents' perception. These are the alarming situation and demand our immediate attention

Key words: Nutritional status, self-perception, parents' perception

TAJ 2019; 32: No-2: 07-13

\section{Introduction}

Indo-Asian countries are now experiencing the unique challenge of rapid rise of childhood obesity despite a persistently high burden of undernutrition. ${ }^{1}$ Undernutrition is a serious public health concern in Bangladesh like other developing countries in Asia. Situation is rapidly becoming worse as overnutrition is also posing a

${ }_{1}$ Assistant Professor (Neonatology), Department of Pediatrics, Rajshahi Medical College, Rajshahi.

2 Professor and Head, Department of Pediatrics, Rajshahi Medical College, Rajshahi.

3 Junior Consultant (Obstetrics and Gynaecology), Upazila Health Complex, Tongibari, Munshiganj.

${ }^{4}$ Assistant Professor (Neonatology), Department of Pediatrics, Chittagong Medical College, Chittagong.

${ }^{5}$ Registrar (Neonatology), Department of Pediatrics, Rajshahi Medical College Hospital, Rajshahi.

${ }^{6}$ Assistant Registrar (Pediatrics), Department of Pediatrics, Rajshahi Medical College Hospital, Rajshahi. 
major threat to already fragile health care system. In one study done on kamar tribal children of central India showed that more than half of the children aged 7-9 years were underweight (54.55\% boys and $56.72 \%$ girls). ${ }^{2}$ Among early adolescents, the prevalence of overweight and obesity reaches $12.2 \%$ and $7.2 \%$ in two regions of Brazil. $^{3}$ Overweight and obesity is now a global epidemic. The prevalence of overweight has tripled worldwide in the last 2 to 3 decades including developing countries. Among children aged 5 to 17 years about 155 million are estimated to be overweight; 30 to 45 million of them are classified as obese. ${ }^{4}$ The calculated global prevalence of overweight and obesity in children aged 5-17 years is found to be approximately 10\% that ranges from $30 \%$ in USA to $<2 \%$ in sub Saharan Africa. ${ }^{5}$

Physical, social and emotional consequences of underweight and overweight may be evident even in very young children and may persist into adulthood. ${ }^{6}$ According to a study done by Guo et al, more than half of the children and adolescents with BMI values at 75th percentile on the new CDC BMI for age growth charts had risk of being overweight as adults. ${ }^{7}$ Children and adolescents with BMI values at 95th percentile had a $62-98 \%$ likelihood of being overweight at 35 years of age. ${ }^{7}$ Evidence suggests that, childhood obesity has been associated with several serious risk factors later in adulthood. Underweight is related to lack of physical fitness, lower school achievement, susceptibility to infection, reduced work capacity, negative self-image, low self-esteem and psychosocial disorder which affect quality of health as early as during childhood, resulting in an increase in disease and morbidity among adolescents and adult. Children with low selfesteem have high level of loneliness, sadness, and nervousness. Overweight is also a complicated disorder that involves multiple organ systems and can lead to potentially devastating consequences. It is considered as an important predictor of longterm morbidity and mortality. It is a major contributor to the development of hypertension, hyperinsulinemia, peripheral insulin resistance, hyperlipidaemia, increased cardiovascular risk and orthopedic complications. ${ }^{7,8}$ These risk increase according to the severity and the duration of the malnutrition. ${ }^{7,8}$ Serious psychosocial consequences: a negative self-image also observed in overweight children as early as 5 years, while obese adolescents have low self-esteem and high risk behavior such as smoking, drug addiction, suicide attempts and suicide. ${ }^{8,9}$ The most prevalent immediate consequences for obese children are social isolation, depression and peer problem. ${ }^{6}$ In an overweight child, depression may manifest as sleep disturbance, hopelessness and sadness, and appetite changes. So, the identification of overweight and obesity in children and adolescent and their management is an important aspect of preventive pediatrics and public health for promotion of physical, social and emotional health of children.

Due to seriousness of the problem resulting from underweight or overweight during childhood, appropriate preventive measure needs to be taken as soon as possible. Any delay in recognition of malnutrition puts the children at additional health risk. But in reality, treatment of underweight and overweight children is very often neglected by parents. Parents tent to only consider malnutrition a problem when there is some type of compromise involved, particularly to physical activity. ${ }^{10}$ Therefore recognition of the actual nutritional status by parents and self should be encouraged. A first step in the treatment of underweight and overweight is to help families recognize their child's malnutrition status. Parents, who do not recognize their child is underweight or overweight, do not feel that that their child's nutritional status represents a problem worthy of intervention. So they may not think of seeking help of a health professional, may not be ready to receive counseling or intervention for underweight or overweight. Childhood underweight or overweight prevention efforts are unlikely to be successful without a better understanding of how parents perceive the problem of underweight or overweight in their children. This study was carried out with the objective of describing and comparing perceptions (parents' and self) of the nutritional status with the actual nutritional status 
measured by BMI. This study might help us to see the magnitude of the problem regarding perception of the nutritional status and draw the attention of the future researcher to find out better strategies to reduce misperception about the child's nutritional status and thus helping families solve their own problem by themselves at an early stage.

\section{Materials and Methods}

This Cross-sectional study was carried out in the Department of Pediatrics, Sir Salimullah Medical College, Mitford hospital, Dhaka over a period of 12 months from July 2008 to June 2009. Multistage sampling (lottery method) was done to collect desired number of sample. In $1^{\text {st }}$ stage, Only one ward was selected by simple random sampling among ninety wards of Dhaka Metropolitan city. In $2^{\text {nd }}$ stage, three schools were selected by simple random sampling from that ward and in $3^{\text {rd }}$ stage; all students from class I to class $\mathrm{X}$, aged 6 to 18 years of either sex were enrolled from these three schools. A selfadministered parents' questionnaire in Bengali along with parents' informed written consent form was used in this study. Each student filled a separate questionnaire by himself or herself or with the help of researcher during class time after receiving parental written consent. Here the role of the researcher was only to clear up any doubts and nobody was allowed to interfere with student's replies. Then student's standing height was measured to the nearest $0.1 \mathrm{~cm}$, making the child stand against the measuring tape attached on a wall. Weight was measured to the nearest of 0.5 $\mathrm{kg}$ without shoes and with light cloths on using a bathroom scale. The BMI was calculated as weight in kilogram divided by height in meters squared. Then the student's nutritional status was defined according to age and gender specific body mass index percentile from CDC-2000 reference as underweight $\left(<5^{\text {th }}\right.$ percentile), normal $\left(5^{\text {th }}-85^{\text {th }}\right.$ percentile), overweight $\left(85^{\text {th }}-<95^{\text {th }}\right.$ percentile), and obese (95th percentile and above).

Parents' perception and self-perception of the nutritional status were compared with the actual nutritional status calculated by BMI. Chi-square test was used for testing statistical significance. Statistical significance was set at $p<0 \cdot 05$. The protocol of the study was approved by the ethical review committee of Sir Salimullah Medical College, Mitford Hospital, Dhaka.

\section{Results}

A total of 1348 students at three schools were enrolled in the study. Out of them 1026 (76.11\%) students who received parental written consent and agreed to participate were considered valid for the study. All 1026 students were assessed for nutritional status. Only 772 parents replied the parent's questionnaire along with written consent form (57.27\% of the 1348 parents).

Table I: Baseline characteristics of school children $(n=1026)$

Age group (in years)

\begin{tabular}{lll} 
& \multicolumn{2}{c}{ Boys } \\
& n & $(\mathbf{\%})$ \\
$6-<10$ & 260 & $(25.3)$ \\
$10-<14$ & 231 & $(22.5)$ \\
$14-18$ & 128 & $(12.5)$
\end{tabular}

Sex

\section{Total}

\begin{tabular}{cc}
\multicolumn{2}{c}{$\begin{array}{c}\text { Girls } \\
\text { n } \quad(\%)\end{array}$} \\
$153 \quad(14.9)$ \\
$174 \quad(17)$ \\
$80 \quad(7.8)$
\end{tabular}

$413(40.2)$

405 (39.5)

$208(20.3)$ 
Table II: Categorization of studied children's nutritional status according to BMI percentile for age and sex:

$\begin{array}{lll}\text { Categorization by BMI } & \text { Number } & \text { Percentage } \\ \text { Underweight } & 425 & 41.4 \\ \text { Normal weight } & 498 & 48.5 \\ \text { Overweight } & 57 & 5.6 \\ \text { Obese } & 46 & 4.5 \\ \text { Total } & 1026 & 100\end{array}$

Table III: Nutritional status of studied children in different age group:

Age group

(in years) Underweight
Normal weight

Overweight
Total

Obese (according to age)

$\begin{array}{cccccc}\text { n } & \text { \% } & \text { n } & \text { \% } & \text { n } & \text { \% } \\ 26 & (6.3) & 24 & (5.8) & 413 & (100) \\ 24 & (5.9) & 14 & (3.5) & 405 & (100) \\ 7 & (3.4) & 8 & (3.9) & 208 & (100) \\ 57 & & 46 & & 1026 & \end{array}$

Chi-square test $=48.9 ; \mathrm{p}<0.0001 ; \mathrm{df}=6$

Table IV: Categorization of children's nutritional status according to sex:

\section{Categorization by BMI}

Underweight

Normal weight

Overweight

Obese

Total

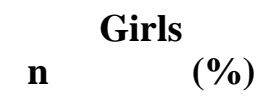

171

211

16

9

407
(42)

(100)

$\begin{array}{ccc} & \text { Boys } & (\%) \\ 254 & & (41) \\ 287 & (46.4) \\ 41 & (6.6) \\ 37 & (6) \\ 619 & (100)\end{array}$


Chi-square test $=54 ; \mathrm{p}=0.0057 ; \mathrm{df}=3$

Chart I showed students self-perception about their nutritional status was correct in $41.3 \%$ (424 among 1026) school children and incorrect in 58.7\% (602 among 1026) school children irrespective of nutritional status and parents perceptions irrespective of children's nutritional status was correct in 51.9\% (401 among 772) and incorrect in 48.1\% (371 among 772 parents).

Chart-I: Self and parents perception of child's nutritional status

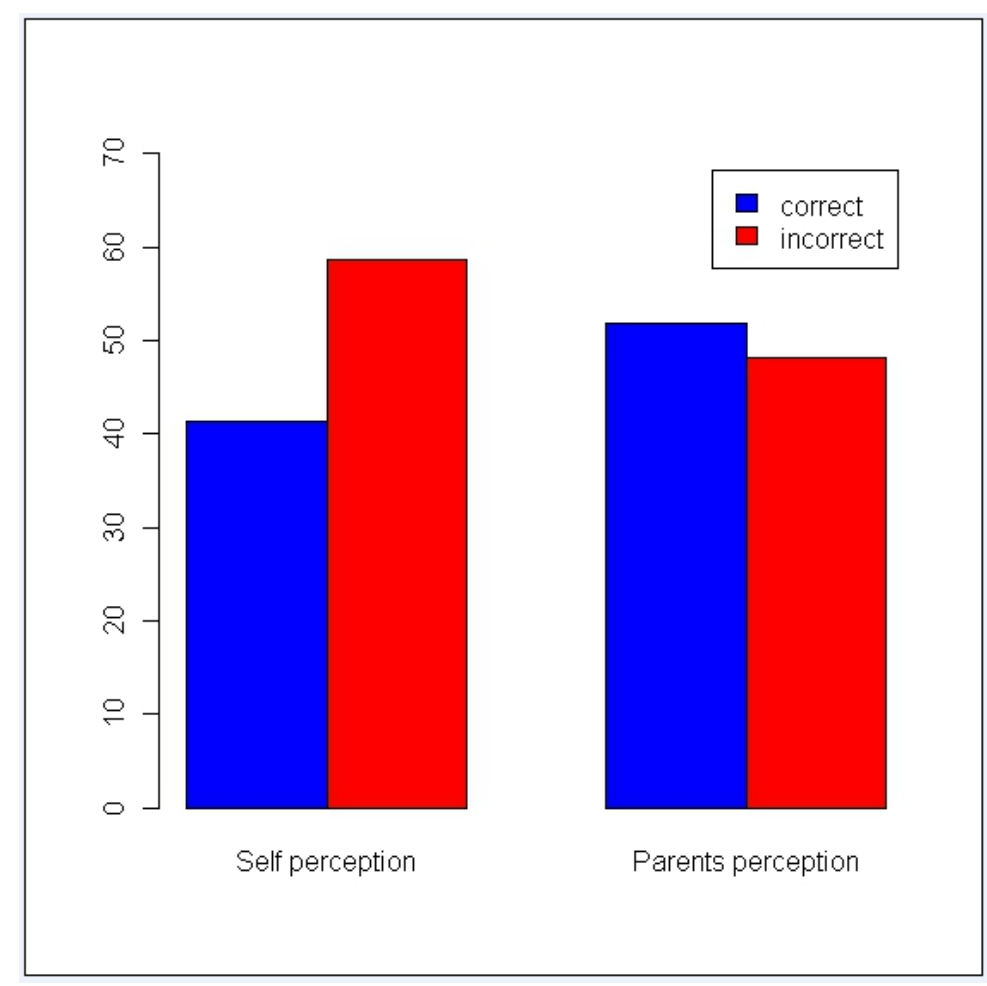

Table V: Self-perception of nutritional status (correct and incorrect) in different nutritional status categorized by BMI:

\begin{tabular}{cccccccr}
$\begin{array}{c}\text { Categorization by } \\
\text { BMI }\end{array}$ & \multicolumn{2}{c}{$\begin{array}{c}\text { Correct self- } \\
\text { perception } \\
\mathbf{n}\end{array}$} & $\begin{array}{c}\text { Incorrect self-perception } \\
\mathbf{( \% )}\end{array}$ & $\mathbf{n}$ & $\mathbf{2}$ & \multicolumn{2}{c}{ Total } \\
Normal weight & 357 & $(71.7)$ & 141 & $(28.3)$ & 498 & $(100)$ \\
Underweight & 37 & $(8.7)$ & 388 & $(91.3)$ & 425 & $(100)$ \\
Overweight & 21 & $(36.8)$ & 36 & $(63.2)$ & 57 & $(100)$ \\
Obese & 9 & $(19.6)$ & 37 & $(80.4)$ & 46 & $(100)$ \\
Total & 424 & & 602 & & 1026 &
\end{tabular}

Chi-square test $=385 ; \mathrm{p}<0.0001 \mathrm{df}=3$ 
Table VI: Parents perception of child's nutritional status (correct and incorrect) in different nutritional status categorized by BMI:

\section{Categorization by BMI}

$\begin{array}{ccc}\text { Normal weight } & 299 & (82.4) \\ \text { Underweight } & 82 & (25.7) \\ \text { Overweight } & 15 & (30.6) \\ \text { Obese } & 5 & (12.2) \\ \text { Total } & 401 & \end{array}$

Chi-square test $=257.5 ; \mathrm{p}<0.0001 \mathrm{df}=3$

\section{Discussion}

This study on 1026 school children (6-18 years) found $41.4 \%$ as underweight, $48.5 \%$ as normal weight, $5.6 \%$ as overweight, and $4.5 \%$ as obese. A study in West Bengal, India in similar age group found $27.9 \%$ as underweight ${ }^{11}$ and another study in Karachi, Pakistan found $27.3 \%$ as underweight, $5.7 \%$ as overweight and obese. ${ }^{1}$ So, all groups were higher in this study. This study therefore highlights the unique challenge faced by schoolaged children in Bangladesh: A rapid increase in the proportion of children with overnutrition in the presence of a persistently high burden of undernutrition.

In this study, total $58.7 \%$ self-perception was incorrect whereas parental perception about their child's nutritional status was incorrect in $48.1 \%$. In a study done on school children $(\mathrm{n}=1741)$ of Brazil, aged 6-19 years showed only 35.2\% had incorrect self-perception and parents' perception ( $n=838)$ was incorrect in $24.7 \%$ cases. ${ }^{12}$ Situation is much worse in the present study.

In the present study $92.3 \%$ underweight school children could not correctly identify themselves as underweight. $63.1 \%$ overweight and $80.4 \%$ obese children also could not correctly identify themselves as overweight and obese respectively. This was very alarming. Percentage of incorrect self-perception among normal weight children was only $28.3 \%$.

\begin{tabular}{lccc}
$\begin{array}{c}\text { Incorrect parents } \\
\text { perception } \\
\mathbf{n}\end{array}$ & \multicolumn{2}{c}{ Total } \\
$\mathbf{( \% )}$ & $\mathbf{n}$ & $\mathbf{( \% )}$ \\
64 & $(17.6)$ & 363 & $(100)$ \\
237 & $(74.3)$ & 319 & $(100)$ \\
34 & $(69.4)$ & 49 & $(100)$ \\
36 & $(87.8)$ & 41 & $(100)$ \\
371 & & 772 &
\end{tabular}

In the present study $74.3 \%$ underweight school children were not correctly identified by their parents as underweight. 69.4\% overweight and $87.8 \%$ obese children were also not correctly identified by their parents as overweight and obese respectively. This was also very alarming. Only $17.6 \%$ parents were unable to correctly identify their normal weight children as normal weight. In a study done on preschool children of USA $80 \%$ mother could not correctly identify their overweight children as overweight. ${ }^{13}$ The tendency to underestimate the weight of children with overweight or obesity was described in a study of 111 Afro- American children aged 5-10 years, where $54 \%$ of mothers had an incorrect perception of their children's weight. ${ }^{14}$ The result of this study was consistent with that of Baughcum et al ${ }^{13}$ but slightly higher than the findings of YoungHyman D et al. ${ }^{14}$

Further research is needed to explore why parents did not perceive their underweight or overweight children to be underweight or overweight. For example, parents may recognize that their child is underweight or overweight but may actively choose not to acknowledge or address it. Parents may not even be aware of the health risks associated with undernutrition or overnutrition. According to Baughcum, among the possible causes that could be responsible for nonrecognition of overweight and obese children by their parents, might be the belief that a "chubby" 
child is healthy and an overweight child represents a caring parent. $^{15}$ Furthermore, many parents believe that as their child grow, the weight will be better distributed and the child will be normal in weight by adolescence. There remains a perception among some parents and children that childhood underweight and overweight are a largely cosmetic problem, with minor clinical effects. ${ }^{15}$

This study had explored the nutritional scenario of school children in our context. This study also showed the magnitude of misperception (self and parents) of child's nutritional status and demand our immediate attention in this alarming situation.

\section{Conclusion}

This study found the double burden of undernutrition and obesity in school children of Dhaka city. Majority of children failed to perceive their actual body image and almost half of the parents also failed to perceive the actual body image of their children. Underweight and obese school children had the most incorrect selfperception. Similarly parents of the underweight and obese children group had the most incorrect parents' perception. These are the alarming situation and demand our immediate attention.

\section{References}

1. Jafar TH, Qadri Z, Islam M, Hatcher J, Butta ZA, Chaturvedi N. Rise in childhood obesity with persistently high rates of undernutrition among urban school-aged Indo-Asian children. Arch Dis child 2008; 93:373-78.

2. Mitra M, Kumar PV, Chakrabarty S, Bharti P. Nutritional status of kamar tribal in Chhattisgarh. Ind J Paediatr 2007; 74(4):381-84.

3. Abrantes MM, Lamounier JA, Colosima EA. Overweight and obesity prevalence children and adolescents from Northeast and Southeast regions of Brazil. Jornal de Pediatria 2002; 78:335-40.

4. Onis MD, Blossner M. Prevalence and trends of overweight among pre- school children in developing countries. Am J Clin Nutr 2000; 72: 1032-39.

5. Lobstein T, Baur I, Urav R. Obesity in children and young people a crisis in public health. International obesity task force $2004 ;$ 5:1-104.

6. Dietz WH. Health consequences of obesity in youth: childhood predictors of adult disease. Pediatrics 1998; 101:518-25.

7. Guo SS, Wu W, Chumlea WC, Roche AF. Predicting overweight and obesity in adulthood from body mass index values in children and adolescences. Am J Clin Nutr 2002; 76:653-58.

8. Au RWM, Low LCK. Obesity: an emerging epidemic problem. HK J Pediatr 2004; 9:340-59.

9. Ogden $\mathrm{CL}$, Fleagal KM, Carrol MD, Johnson CL. Prevalence and trends in overweight among US children and adolescents. JAMA 2002; 288:172832.

10. Etelson D, Brand DA, Patrick PA, Shirali A. Childhood obesity: do parents recognize this health risk? Obes Res 2003; 11:1362-68.

11. Bose K, Bisai S. Prevalence of underweight and stunting among school children in West Bengal. Indian J Pediatr 2008; 75:1272-78.

12. Sorte BS, Neri LA, Leite MEQ, Brito SM, Meirelles AR, Luduvice FBS, Santos JP, Viveiros MR, Ribeiro-jr HC. Maternal perception and selfperception of the nutritional status of children and adolescents from private schools. Jornal de Pediatria 2007; 83(4):349-56.

13. Baughcum AE, Chamberlin LA, Deeks CM, Powers SW, Witaker RC. Maternal perceptions of overweight preschool children. Pediatrics 2000; 6:1380-86.

14. Young-Hyman D, Herman LJ, Scott DL, Schlundt DG. Caregiver perception of the children's obesity related health risk: a study of African American families. Obes Res 2000; 8:241-48.

15. Baughcum AE, Burklow KA, Deeks CM, Powers SW, Whitaker RC. Maternal feeding practices and chldhood obesity: a focus group group study of lowincome mothers. Arch Pediatr Adolesc Med 1998; 152(10):1010-14. 